\title{
Did the Cholera epidemic in Haiti really start in the Artibonite Department?
}

\author{
Rafael Llanes, Lorenzo Somarriba, Plácido Pedroso, Emiliano Mariscal, Carlos Fuster, Yamila Zayas \\ Cuban Medical Brigade in Haití, Port au Prince, Haiti
}

Key words: cholera epidemic; Haiti

J Infect Dev Ctries 2013; 7(10):753-755. doi:10.3855/jidc.3311

(Received 12 January 2013 - Accepted 12 March 2013)

Copyright (C) 2013 Llanes et al. This is an open-access article distributed under the Creative Commons Attribution License, which permits unrestricted use, distribution, and reproduction in any medium, provided the original work is properly cited.

The last cholera epidemic in the Western Hemisphere began in 1991 and lasted for nearly a decade, spreading across Central and South America, but not to the Caribbean islands [1].

On 18 October 2010, during the working session at the Situational Room, Laboratoire Nationale de Santé Publique (LNSP) in Port au Prince, Haiti, an epidemiologist of the Cuban Medical Brigade (CMB) warned the participants about an unusual increase in the number of severe watery diarrhoea cases with dehydration and three deaths at the community reference hospital (CRH) of Mirebalais, located in Haiti's Centre Department.

A multidisciplinary team of the CMB was dispatched to the affected area on 19 October to investigate. In addition, the Haitian Ministry of Public Health and Population (MSPP) declared a health alert and provided guidance to health authorities of the Centre Department for field analysis and decision making.

The Cuban Co-director of the CRH in Mirebalais explained that the first case with severe watery diarrhoea and dehydration was admitted to the hospital on 16 October but the majority of hospitalized cases and deaths occurred on 18 October. Some patients were reported in serious condition and required life support. Findings from our research investigation showed that clinical manifestations began 12 to 24 hours before clinical admission of these patients to the hospital. From 17 to 18 October, two children of three and five years of age died.

On 19 October, exchange between the Cuban team and local health authorities of the Centre Department, which conducted parallel investigations, revealed the following measures taken: 1) collection and shipping of stool samples to the LNSP for laboratory isolation and confirmation; 2) dissemination of messages to the community, by radio and talks, about the control and prevention of diarrhoeal diseases, spoken in the Creole language; 3) supplying of chlorine to treat drinking water in the affected sites.

The CMB inspected five sites where cases and deaths related to the diarrhoea occurred: Meille, Montagne Terrible, Rue Louverture, Chateau, and Gravelot. They were located less than 100 meters from the Latem and Jamba Rivers, in Mirebalais, which are tributaries of the Artibonite River. Families living in these areas lacked basic hygiene habits, with evident household overcrowding. The presence of outdoor defecation and abundant vectors (flies) were observed in all dwellings visited. Most importantly, this population used the water of the Artibonite River for their daily activities: drinking, bathing, and washing their clothes.

It was noted and later reported by Piarroux et al. [2] that sewage water dripped into the Artibonite River, and its tributaries, in several places in the locality. The rains of recent days had dragged the contents of the river, which included outdoor defecation and sewage materials, from the latrines. All these environmental/biological wastes augmented the contamination of the river, which was used by local habitants for several human activities, including drinking.

A follow-up inspection to the CRH of Mirebalais showed that seven patients ranging from 5 to 60 years of age were hospitalized. Previously, they had received oral or parenteral rehydration therapy and antibiotics. At such time, all patients were free of diarrhoea and vomiting with a good outcome.

The LNSP confirmed the presence of Vibrio cholerae serogroup O1, biotype El Tor, and serotype 
Figure 1. Artibonite river and communes in which the initial cases of diarrhoeal episodes were detected

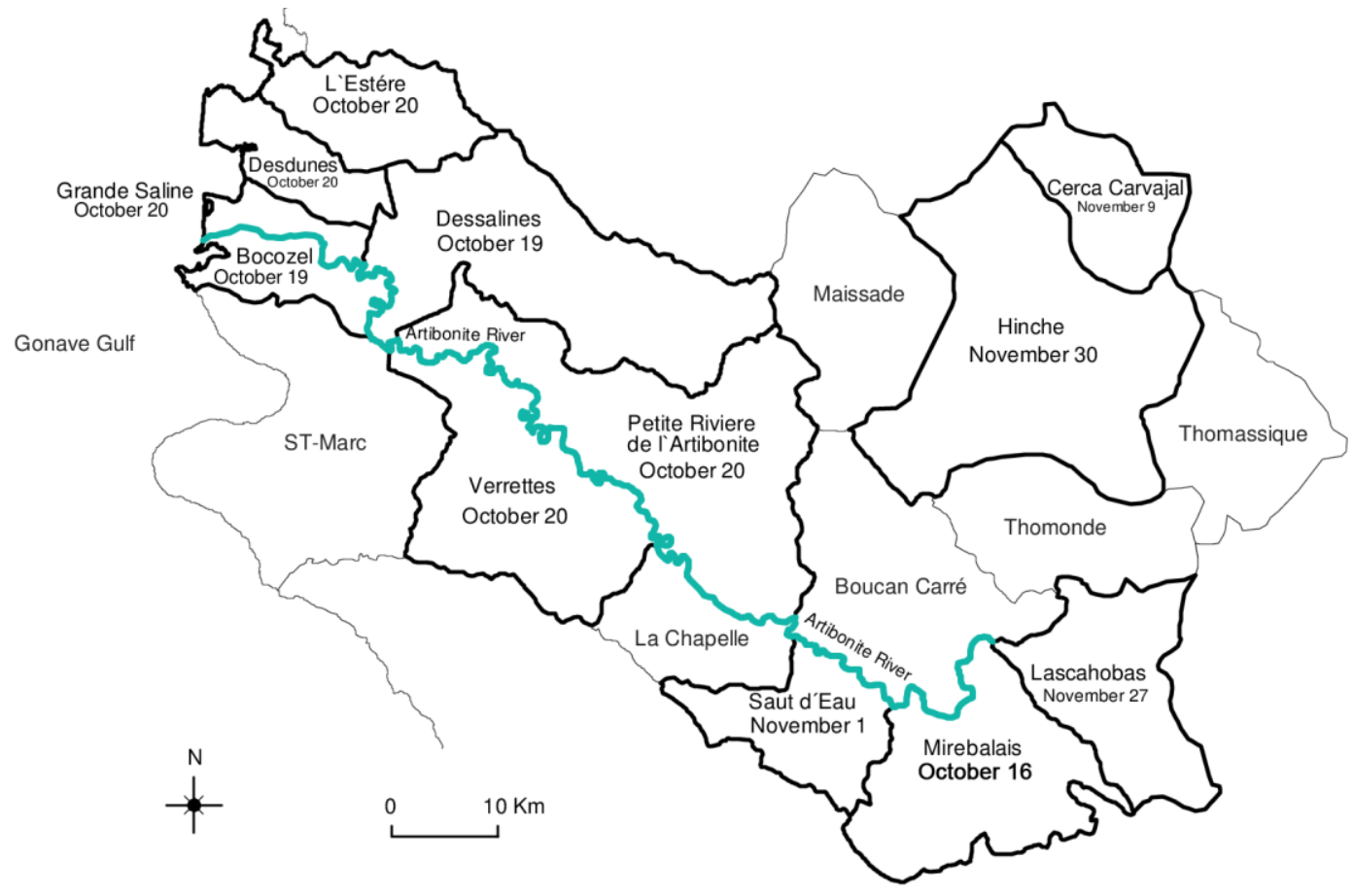

Ogawa in five out of six stool samples received on 19 October from patients of the Meille village in Mirebalais.

The rapid and timely warning issued by the CMB to the MSPP facilitated the initial epidemiological investigation and outbreak control. The source of infection and rapid dissemination was contamination of the Artibonite River and its delta, which runs by the Centre Department and continues downstream to penetrate and cross the Artibonite Department, which empties into the sea. On 19 October 2010, the diarrhoeal episodes and deaths escalated in the Lower Artibonite area in Bocozel (commune of Saint Marc) and the commune of Dessalines. On 20 October 2010, the communes of Grande Saline, Desdunes, Petite Riviere de l'Artibonite, L'Estere and Verrettes also reported diarrhoeal episodes and deaths. All these communes belong to the Artibonite Department. In contrast, in other communes of the Centre Department, including Hinche, Lascahobas, Saut d'Eau and Cerca Carvajal, which are not crossed by the Artibonite delta, cholera cases appeared at the end of October and into November 2010 (see Figure 1). On 21 October, the Haitian MSPP officially declared that Haiti was in the middle of a cholera epidemic [2].

In conclusion, the current report clarifies that the first cases of cholera in Haiti occurred at the Centre Department and not in the Artibonite Department, as many publications reported $[3,4,5]$. Interestingly, the first patients with severe diarrhoea and dehydration hospitalized at the HCR of Mirebalais (from October 16-18) were children younger than 14 years (63.7\%, 21/33), including the two patient deaths. During cholera epidemics, it is well documented that first cases and deaths occur generally in the adult population $[6,7]$.

\section{Acknowledgements}

The authors are gratefulto LNSP for laboratory confirmation of $V$. cholerae isolates and to Mrs. Laurie Atkinson for English revision.

\section{References}

1. Poirier MJP, Izurieta R, Malavade SS, McDonald MD (2012) Re-emergence of cholera in the Americas: Risks, Susceptibility, and Ecology. J Glob Infect Dis 4: 162-171.

2. Piarroux R, Barrais R, Faucher B, Haus R, Piarroux M, Gaudart J, Magloire R, Raoult D (2011) Understanding the cholera epidemic, Haiti. Emerg Infect Dis 17:1161-1168.

3. Centers for Disease Control and Prevention (2010) Cholera Outbreak-Haiti, October 2010. Morb Mortal Wkly Rep 59: 11.

4. Walton DA, Ivers LC (2011) Responding to cholera in PostEarthquake Haiti. N Engl J Med 364: 3-5.

5. Mukandavire Z, Smith DL, Morris JG Jr. (2013) Cholera in Haiti: Reproductive numbers and vaccination coverage estimates. Sci Rep 3 : 997. doi: 10.1038/srep00997

6. Kyelem CG, Bougoma A, Thiombiano RS, Salou-Kagoré IA, Sangaré L, Ouédraogo R (2011) Epidemié de cholera au Burkina Faso en 2005: aspects épidemiologiques et diagnostiques. Pan Afr Med J 8: 1 
7. Centers for Disease Control and Prevention (2010) Update: Cholera Outbreak-Haiti, 2010. Morb Mortal Wkly Rep 59: 1473-1479.

\section{Corresponding author}

Dr. Rafael Llanes

Brigada Médica Cubana en Haití

Delmas 83, e/ Canal y La Sirena 53

Post Code HT 6120

Port au Prince, Haití

Telephone: 50937011663

Email: 1lanesrafael2002@yahoo.com

Conflict of interests: No conflict of interests is declared. 